\title{
Commentary
}

\section{Food environments and the COVID-19 pandemic in Brazil: analysis of changes observed in 2020}

\begin{abstract}
Evidence of changes caused by the COVID-19 pandemic in food security and nutrition conditions, as well as in different food environments, has called researchers' attention to substantial changes taking place in individuals' dietary babits. The aim of this study is to present and address changes that have already happened in food environments, during the first COVID-19 pandemic year, in a middle-income country. Multiple changes were observed and had direct impact on the population, among them, worsened bealth and nutrition indicators and advanced dietary inequalities, as well as on its food profile in different life cycles, if one takes into consideration aspects such as food availability, financial access and dietary quality.
\end{abstract}

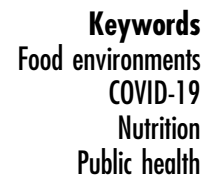

There is an evidence that the global pandemic triggered by the emergence and spread of the new human coronavirus (SARS-CoV-2), which was declared by the WHO in March $2020^{(1)}$, has had effects on food systems worldwide. Food environments in most countries have rapidly experienced changes in their external dimensions, such as food availability, prices, suppliers, as well as in personal dimensions, such as geographic accessibility, affordability and convenience. Rapid changes in food environments can influence consumers' eating habits, as well as worsen national health and nutrition indicators ${ }^{(2-4)}$.

One year after the beginning of the COVID-19 pandemic, several uncertainties about changes in its features remain in different food environments and contribute to the advancement of food and nutrition insecurity ${ }^{(5-8)}$, as well as to worsen health, income, employment and education conditions ${ }^{(9-13)}$. The aim of this study is to present and address changes that have already taken place in food environments during the first COVID-19 pandemic year in a middle-income country.

\section{Food environments and their modifications}

At the beginning of the COVID-19 pandemic in Brazil and in several countries worldwide, the fear of food shortage has led part of the population to purchase great amounts of processed and ultra-processed food due to its durability, practicality and easy access in different physical and online food environments ${ }^{(3,14)}$. Moreover, consumers' perception about the risks they are exposed to and the impact of this perception on their intention and decision to purchase food should also be taken into consideration. Thus, the perception of risk associated with food supply at the beginning of COVID-19 pandemic has influenced individuals' eating behaviour ${ }^{(3)}$ and led them to use delivery services rather than going to the physical store.

The worsening of the COVID-19 pandemic in several Brazilian cities has led to the need of taking harder measures about social distancing, as well as to security determinations focussed on reducing human circulation and the consequent spread of the virus. These measures comprised closing public food procurement sites such as municipal markets and open fairs, as well as restricting physical access to establishments selling food for immediate consumption such as restaurants and snack bars ${ }^{(2,15)}$. In addition, many traders have changed the selling pattern of their establishments in order to meet community demands and to reduce the impact of the crisis ${ }^{(16)}$. These measures have contributed to change the physical retail food environment ${ }^{(17)}$ through the migration of many establishments, mainly those that sell food for immediate consumption, to the virtual environment ${ }^{(2)}$.

These sudden changes have significantly changed consumers' profile since they started purchasing food through several applications and websites of the most varied foodselling establishment categories. Digital food environment has undergone significant increase in takeout/away and delivery services during the pandemic, mainly because Brazilian regulations have ordered many mass catering establishments to be closed, whereas many others had to migrate to the virtual environment ${ }^{(2)}$.

Unhealthy-ultra-processed food types, such as hamburgers, pizzas, sweets in general, sugary drinks, among others, 'are more available' in these food purchase convenience channels ${ }^{(18,19)}$. The access of different consumers to the digital environment, mainly due to issues such as

(C) The Author(s), 2021. Published by Cambridge University Press on behalf of The Nutrition Society. This is an Open Access article, distributed under the terms of the Creative Commons Attribution licence (http://creativecommons.org/licenses/by/4.0/), which permits unrestricted re-use, distribution, and reproduction in any medium, provided the original work is properly cited. 
physical distance between the residences and the establishments, convenient access to food and beverages ${ }^{(19)}$ and overload of household activities, may contribute to the development of unhealthy eating habits in the mid and long term ${ }^{(20,21)}$.

The digital food environment - which has been rapidly expanding in Brazil ${ }^{(19)}$ — presents similar profile to all other digital categories when it comes to the influence of advertising on individuals' food choices. This factor implies food promotion and advertising in the most different media and it may lead to unhealthy food choices $^{(7,22)}$.

Consumers have been facing issues in the food environment such as worsened food affordability ${ }^{(23)}$. Data have shown increased price of basic food items such as rice, beans and coffee powder, since the beginning of the pandemic in Brazil. Calculations made by the InterUnion Department of Statistics and Socioeconomic Studies (DIEESE), based on data from the National Basic Food Basket Survey, have shown an increase in all 17 surveyed capitals that have recorded the highest annual increase in food prices in $2020^{(23)}$.

In addition, consumers' loss of purchasing power had significant impact on family farming, since farmers depend on local supply and on decentralised food marketing systems ${ }^{(24)}$ to generate income. Furthermore, a study about socioeconomic conditions in Brazil has pointed out remarkably negative impacts of the COVID-19 pandemic on family income ${ }^{(25)}$, which can substantially lead to deleterious effects on food purchasing, mainly when it comes to the quantity and quality of purchased products. Unexpectedly some web surveys results are not showing a worsening diet quality during the pandemic period. The Nutrinet Brazil survey, which started in January 2020, back in May, 2020, showed slight increase in the consumption of healthy eating markers and stability in the consumption of unhealthy eating markers in most sociodemographic strata during the COVID-19 pandemic, except for the Northern and Northeastern macroregions in Brazil, which showed trend of increased ultra-processed food consumption $^{(26)}$. However, results should be interpreted with caution, since it is a cohort study conducted with nonprobabilistic sample and with reduced absolute number of participants in some macroregions and income strata under greater vulnerability condition ${ }^{(26)}$

Most changes in food environments resulting from the pandemic may be contributing to modify food consumption among Brazilians. The Brazilian survey ConVid, conducted between April and May 2020, during the social distancing period, pointed out higher alcoholic beverage intake, decreased frequency of healthy food intake and increased frequency of unhealthy food intake due to the COVID-19 pandemic, except among the elderly population $^{(27)}$

Accordingly, a cross-sectional study was conducted with 820 adolescents in the age group 10-19 years, from different countries, including Brazil, during the pandemic, from April to May 2020. It was based on an online questionnaire distributed by social media such as WhatsApp and Twitter, and showed changes in food intake. On the one hand, there was increased vegetable intake, mainly in Brazil. On the other hand, the mean fried food and sweet intake have significantly increased during the forced confinement imposed on participants due to the COVID-19 pandemic $^{(28)}$.

With respect to the school food environment, it is known that physical distancing measures have led to school closure and had negative impact on students' education and nutritional status. When it comes to public schools, the National School Food Program (Programa Nacional de Alimentação Escolar) accounts for ensuring adequate food for Brazilian schoolchildren during school days $^{(29)}$. However, this process was initially interrupted by the pandemic; besides, the inefficient and delayed federal guidance by the National Education System regarding National School Food Program has generated multiple and discrepant actions by state and local authorities ${ }^{(30)}$. Thus, on 7 April 2020, the distribution of foodstuffs purchased with federal funds to schoolchildren's parents or legal guardians was officially authorised countrywide ${ }^{(31,32)}$.

With respect to school feeding strategies adopted by state and local governments, some places used their own resources to deliver non-family farming food baskets while others performed direct cash transfer through food card/ value, ${ }^{(29,30)}$ and some, to a lesser extent, delivered food baskets purchased from small family farmers ${ }^{(30)}$.

It is noteworthy that distributing food baskets without properly planning the nutritional quality of the provided food can undermine the work of Food and Nutrition Education (Educação Alimentar e Nutricional), which has been carried out by National School Food Program over the years. The aim of Food and Nutrition Education, which is in line with the dietary guidelines for the Brazilian population $^{(33)}$, is to promote the intake of fresh and healthy foods such as fruits, vegetables and legumes, including food items belonging to local cultures and farmers. Its interruption can damage the adequate and healthy diet of schoolchildren $^{(34)}$.

Studies conducted before the COVID-19 pandemic have shown that private schools presented a more obesogenic food environment than public schools ${ }^{(35)}$. Face-to-face classes in private schools were quickly replaced by online classes; however, the same did not happen in public schools. Also, the excessive use of electronic devices and lack of contact with peers can influence sleep patterns, change eating habits, as well as trigger stress and anxiety behaviours $^{(36)}$. Cafeteria owners who sell food in private schools have seen their economic activity suddenly paralysed and suffered great economic impact due to the COVID-19 pandemic. Consequently, changes in ownership, in places where food is sold and in the type of food 
sold are expected when presential activities return. Thus, it is of paramount importance to think about strategies to reverse, rather than to worsen, the obesogenic food environment in private schools when the classroom activities return.

\section{Final considerations}

The conditions generated by the pandemic in recent months, mainly when lockdown and physical distancing were adopted as strategies to stop disease transmission, have reduced individuals' access to healthy food and contributed to increased social and dietary inequalities, as well as to disparity in health-related behaviours. This scenario has considerably influenced the nutritional condition of the population, such as nutritional status, hunger and food and nutrition insecurity ${ }^{(29,37)}$.

Besides the web surveys have been showing some healthy diet trends at different times in 2020, the COVID-19 pandemic is expected to increase dietary inequalities expressed in different food environments, at their different dimensions. It is essential and demanding to address different food environments, as well as their reflex on human health, mainly in the scope of regulatory policies focussed on promoting the availability of, and financial access to, food.

The retail food environment is undergoing several changes associated with the availability of and financial accessibility to food during the current COVID-19 pandemic. These changes have a direct impact on populations' eating profile, which, in its turn, affects their eating habits and triggers nutritional issues.

Facing this scenario, some actions could be taken in the short, medium or long term. In the short term, confronting COVID-19 requires that school feeding programs continue to be designed for school children's families, promoting support for small farmers and family farming ${ }^{(38)}$. Actions such as encouraging cooking skills, growing one's own food and reducing food waste are also necessary ${ }^{(39)}$. In the medium and long term, actions to address nutritional issues such as food insecurity and obesity by strengthening intersectoral health actions are important and include compliance with health protocols to ensure the supply, access, promotion, purchase and consumption of healthy foods ${ }^{(7)}$. Strengthening actions for food labelling and urban planning that encourages physical activity are also relevant strategies $^{(39)}$.

Finally, it is worth emphasising that the catastrophic situation observed in Brazil during the COVID-19 pandemic and the political inertia towards food and nutritional security actions may result in the potential worsening of health and nutrition indicators ${ }^{(10)}$. In addition, Brazil will likely remain on the hunger map in the coming years, as well as face the risk of increasing obesity prevalence in all life cycles.

\section{Acknowledgements}

Acknowledgements: Not applicable. Financial support: This research received no specific grant from any funding agency in the public, commercial or not-for-profit sectors. Conflicts of interest: None of the authors had a personal or financial conflict of interest. Authorship: L.L.M. contributed to the conception and elaboration of the article; C.D.S., A.M.L., J.M.Z., C.L.O. and P.M.C. contributed to the elaboration and participated in the review of the article. All authors contributed reviewing the manuscript critically for important intellectual content and participated to approval of the version of the manuscript to be published. Ethics of buman subject participation: Not applicable.

Larissa Loures Mendes $^{1, *}$, Daniela Silva Canella ${ }^{2}$, Melissa Luciana de Araújo ${ }^{3}$, Mariana Zogbi Jardim ${ }^{4}$ (D), Letícia de Oliveira Cardoso ${ }^{5}$ and Milene Cristine Pessoa ${ }^{1}$

${ }^{1}$ Nutrition Department, Federal University of Minas Gerais, Avenue Alfredo Balena, 190, Room 314, Santa Efigênia, Belo Horizonte, MG 30130-100, Brazil

${ }^{2}$ Institute of Nutrition, Rio de Janeiro State University, Rio de Janeiro, RJ, Brazil

${ }^{3}$ Program in Health and Nutrition, School of Nutrition, Federal University of Ouro Preto, Morro do Cruzeiro, Ouro Preto, MG, Brazil

${ }^{4}$ Program in Child and Adolescent Health, Federal University of Minas Gerais, Belo Horizonte, MG, Brazil

${ }^{5}$ Epidemiology Department, National School of Public Health, Oswaldo Cruz Foundation, Rio de Janeiro, RJ, Brazil

*Corresponding author: Email larissa.mendesloures@gmail.com

\section{References}

1. WHO (2020) Coronavirus Disease (COVID-19) Pandemic. Geneva: World Health Organization.

2. Oliveira KH de, Soares CES \& Lima JN de P (2020) Food and nutritional security of the Brazilian population in times of pandemic: to whom is nutrition science addressed? J Food Cult Am 2, 151-164.

3. Khatib ASE (2020) Food Stockpiling During the COVID-19 Pandemic: An Analysis in Light of the Theory of Planned Behavior (TPB). In CLAV 2020. http://bibliotecadigital.fgv. br/ocs/index.php/clav/clav2020/paper/view/7378 (accessed February 2021).

4. UNSCN Secretariat (2021) The COVID-19 Pandemic is Disrupting People's Food Environments: A Resource List on Food Systems and Nutrition Responses. https://www. unscn.org/uploads/web/file/COVID-19-Nutrition-ResourcesUNSCN-Feb-2021.pdf (accessed March 2021). 
5. CEPAL (2018) Social Panorama of Latin America 2018. https://repositorio.cepal.org/bitstream/handle/11362/44395/ 11/S1900051_es.pdf (accessed January 2021).

6. Ahmed F, Ahmed N, Pissarides Cet al. (2020) Why inequality could spread COVID-19. Lancet Public Health 5, e240.

7. FAO (2020) Food Systems and COVID-19 in Latin America and the Caribbean $N^{\circ}$ 10: Food Consumption Patterns and Malnutrition. Santiago: FAO.

8. Downs SM, Ahmed S, Fanzo J et al. (2020) Food environment typology: advancing an expanded definition, framework, and methodological approach for improved characterization of wild, cultivated, and built food environments toward sustainable diets. Foods $\mathbf{9}, 532$.

9. Brazilian Institute of Geography and Statistics (editor) (2019) Housebold Budget Survey, 2017-2018: First Results. Rio de Janeiro: IBGE.

10. Alpino T de MA, Santos CRB, Barros DC de et al. (2020) COVID-19 and food and nutritional (in)security: action by the Brazilian Federal Government during the pandemic, with budget cuts and institutional dismantlement. Cad Saúde Pública 36, e00161320.

11. Zachary Z, Brianna F, Brianna L et al. (2020) Self-quarantine and weight gain related risk factors during the COVID-19 pandemic. Obes Res Clin Pract 14, 210-216.

12. Sidor A \& Rzymski P (2020) Dietary choices and habits during COVID-19 lockdown: experience from Poland. Nutrients 12, 1657.

13. Ghosal S, Arora B, Dutta K et al. (2020) Increase in the risk of type 2 diabetes during lockdown for the COVID19 pandemic in India: a cohort analysis. Diabetes Metab Syndr 14, 949-952.

14. Oliveira TC, Abranches MV \& Lana RM (2020) Food (in) security in the context of the SARS-CoV-2 pandemic. Cad Saúde Pública 36, e00055220.

15. Martinelli SS, Cavalli SB, Fabri RK et al. (2020) Strategies for the promotion of healthy, adequate and sustainable food in Brazil in times of Covid-19. Rev Nutr 33, e200181.

16. Leone LA, Fleischhacker S, Anderson-Steeves B et al. (2020) Healthy food retail during the COVID-19 pandemic: challenges and future directions. Int J Environ Res Public Health 17, 7397.

17. Chang M, Green L \& Cummins S (2020) All change. Has COVID-19 transformed the way we need to plan for a healthier and more equitable food environment? Urban Des Int 26, 1-5.

18. Horta PM, Souza J de PM, Rocha LL et al. (2020) Digital food environment of a Brazilian metropolis: food availability and marketing strategies used by delivery apps. Public Health Nutr 24, 544-548.

19. Botelho LV, Cardoso L de O \& Canella DS (2020) COVID-19 and the digital food environment in Brazil: reflections on the influence of the pandemic on the use of food delivery apps. Cad Saúde Pública 36, e00148020.

20. Tribst AAL, Tramontt CR \& Baraldi LG (2021) Factors associated with diet changes during the COVID-19 pandemic period in Brazilian adults: time, skills, habits, feelings and beliefs. Appetite 163, 105220.

21. Tokarski C \& Pinheiro L (2021) Remunerated domestic work and Covid-19: deepening vulnerabilities in a precarious occupation. BAPI, 55-64.

22. Rodrigues MB, Souza J de PM \& Horta PM (2020) The COVID-19 pandemic and its implications for the food information environment in Brazil. Public Health Nutr 24, $321-326$

23. Dieese (2021) National Survey of the Basic Food Basket Special Price Survey for December 2020 and the Year 2020. https://www.dieese.org.br/analisecestabasica/2020/ 202012cestabasica.pdf (accessed March 2021).

24. Schneider S, Cassol A, Leonardi A et al. (2020) The effects of the Covid-19 pandemic on agribusiness and food. Estud Avançados 34, 167-188.

25. Almeida LFF, Novaes TG, Pessoa MC et al. (2020) Socioeconomic disparities in the community food environment of a medium-sized city of Brazil. Null 40, 253-260.

26. Steele EM, Rauber F, Costa C dos S et al. (2020) Dietary changes in the NutriNet Brasil cohort during the Covid-19 pandemic. Rev Saúde Pública 54, 91.

27. Malta DC, Morais Neto OL de \& Silva JB da Jr (2011) Presentation of the strategic action plan for coping with chronic diseases in Brazil from 2011 to 2022. Epidemiol Serv Saúde 20, 425-438.

28. Ruiz-Roso MB, de Carvalho Padilha P, Mantilla-Escalante DC et al. (2020) Covid-19 confinement and changes of adolescent's dietary trends in Italy, Spain, Chile, Colombia and Brazil. Nutrients 12, 1807.

29. Ribeiro-Silva R de C, Pereira M, Campello T et al. (2020) Covid-19 pandemic implications for food and nutrition security in Brazil. Ciênc Saúde Colet 25, 3421-3430.

30. Pereira A da S, Campos FM, Santos CRB et al. (2020) Challenges of the national school meals program during the COVID-19 pandemic. BJD 6, 63268-63282.

31. Amorim ALB de, Ribeiro JRS Jr, Bandoni DH et al. (2020) National school feeding program: strategies to overcome food insecurities during and after the COVID-19 pandemic. Rev Adm Pública 54, 1134-1145.

32. Brazil (2020) Resolution No. 02, of April 9, 2020. https:// www.in.gov.br/web/dou/-/resolucao-n-2-de-9-de-abril-de2020-252085843 (accessed January 2021).

33. Brazil (2014) Dietary Guidelines for the Brazilian Population. Brasília: Ministry of Health, Department of Health Care, Department of Primary Care. 150.

34. Henriques P, O'Dwyer G, Dias PC et al. (2018) Health and Food and Nutritional Security Policies: challenges in controlling childhood obesity. Ciên Saúde Colet 23, 4143-4152.

35. Carmo AS do, Assis MM de, Cunha C de F et al. (2018) The food environment of Brazilian public and private schools. Cad Saúde Pública 34, e00014918.

36. Wang YC, Vine S, Hsiao A et al. (2015) Weight-related behaviors when children are in school versus on summer breaks: does income matter? J Sch Health 85, 458-466.

37. Huizar MI, Arena R \& Laddu DR (2020) The global food syndemic: the impact of food insecurity, malnutrition and obesity on the healthspan amid the COVID-19 pandemic. Progr Cardiovasc Dis 64, 105-107.

38. Welthungerhilfe (2020) Covid-19: The Current Health Crisis Could Trigger A Food Crisis. https://www.welthungerhilfe. org/news/publications/detail/covid-19-the-current-healthcrisis-could-trigger-a-food-crisis/ (accessed February 2021).

39. Helble M (2020) Economic Strategies to Promote Healthy Food Environments Amid the COVID-19 Pandemic. https:// www.who.int/docs/default-source/searo/ncd/dr-matthiaseconomic-strategies-to-promote-healthy-food-environmentsin-the-context-of-covid-19.pdf?sfvrsn=89012edc_4 (accessed February 2021). 